\title{
Purity and Danger in the Modern University
}

\author{
Peter Baehr
}

Published online: 21 May 2011

(C) Springer Science+Business Media, LLC 2011

No portent by a Republican president is cited with greater approval by academics than Dwight Eisenhower's specter of a "military industrial complex" menacing American society. "Unwarranted influence" and "misplaced power," Eisenhower counseled, threatened to erode liberty from within. Less often recalled is Eisenhower's other fear, stated in the same valedictory, about the forces working to subvert the modern university. Speaking at the height of the cold war, the President's eyes were fixed on the impact of Federal Government disbursements on traditional notions of scholarship. The thought that Western universities would one day accept money from dictators was, in 1961, still inconceivable. "Today," he wrote:

The solitary inventor, tinkering in his shop, has been overshadowed by task forces of scientists in laboratories and testing fields. In the same fashion, the free university, historically the fountainhead of free ideas and scientific discovery, has experienced a revolution in the conduct of research. Partly because of the huge costs involved, a government contract becomes virtually a substitute for intellectual curiosity. For every old blackboard there are now hundreds of new electronic computers. The prospect of domination of the nation's scholars by Federal employment, project allocations, and the power of money is ever present and is gravely to be regarded. Yet, in holding scientific research and discovery in respect, as we should, we must also be alert to the equal and opposite danger that public policy could itself become the captive of a scientific-technological elite. It is the

\section{P. Baehr $(\square)$}

Department of Sociology and Social Policy, Lingnan University, Castle Peak Road,

New Territories, Hong Kong

e-mail: pbaehr@LN.edu.hk task of statesmanship to mold, to balance, and to integrate these and other forces, new and old, within the principles of our democratic system - ever aiming toward the supreme goals of our free society (http:// www.h-net.org/ hst306/documents/indust.html).

Eisenhower made two separate if related points. The first was that Federal projects and government employment were corrupting the scientific calling. The second was that scientists themselves might become an anti-democratic clique. The LSE imbroglio offers a bizarre twist on Ike's forebodings. Social scientists acting in the name of democracy accepted funds from a despot's family with the aim of eventually removing that family's despotism - or at least believing that such money would help push gently a despot in the direction (somewhere in the vicinity of Norway) that he was heading anyway. How was that notion possible? The answer is not to be found in the character of Lord Desai, David Held, Anthony Giddens and others. It lies, more fundamentally, in the entrepreneurial, grant-donor culture of the modern research university, in its accretion of ambitions and, among these ambitions, the commitment of social scientists to use the university as an engine of political progress. The LSE scandal is a sideshow in a larger drama.

$$
* * * * *
$$

Before the Second World War, it was common for academics to view state entanglements in the university with repugnance or at least suspicion. Private corporations too were held at arms length. The sociologist Robert Nisbet recalled that when, during the 1930s, the Shell Oil Company offered Berkeley a million dollars donation to found "The Shell Professorship in Chemistry," the chemistry department, led by Gilbert Lewis, revolted. In revealing language, Nisbet adds that while money from foundations such as Rockefeller, Carnegie, Russell Sage and Rosenwald 
was "considered clean," money from corporations like Shell was considered "as tainted as it would have been had it come from the Vatican, the Republican Party, or the Department of Commerce" (Nisbet 1992: 206). The war eroded much of that disdain. National emergency and the good fight overwhelmed academic scruples, razing the boundaries between the state, on the one hand, and the guild of scholars on the other. The prestige of "research," as distinguished from individual scholarship, increased; and the prestige of researchers, as distinguished from teachers, rose correspondingly. By the late 1950s, universities in America were a veritable mushroom field of institutes, centers, and bureau. University academics routinely added consultancies to their growing portfolio.

As student numbers proliferated in the 1960 s, so too did the functions of the university. Since then it is no longer enough that professors engage in scholarship and teaching, no longer enough that they add to human knowledge, its dispersal and critical appropriation. Today they must be researchers in a special way. Their competence and quality is measured by their ability to procure grants. They are also expected, in growing numbers, to be social workers to society at large, a clerisy ministering to the collective soul. Civic engagement, social entrepreneurship, service learning; these are the new responsibilities that the university must discharge in its redemptive mission to make society good. In this milieu, the solo university scholar looks as antediluvian as Ike's "solitary inventor, tinkering in his shop," a fossil derided by a growing army of university administrators as unproductive, self-centered - and redundant. Never mind that academics often admit in private that large-team research routinely produces mediocre results as its participants seek a harmonious final report rather than acknowledge anomalies and pronounced differences of opinion.

Similar developments emerged in Britain, initially at a slower pace and funded less generously. Yet because Britain is a far more centralized nation than the United States, government policy in education has more drastic and standardizing effects. In my last year (1989) of teaching in a British university, the Dean of Arts already employed a language borrowed from Japanese manufacturing. Course delivery, he said at one faculty Retreat, could be produced "just-in-time". Curricula might be truncated to "minimodules" and "learning packages" so as to facilitate student consumption. Simultaneously, language from the private sector was ingeniously welded to progressive causes. Expanding student access was key. Feminists and equal opportunities advocates were quick to see brilliant career opportunities. Women's health was one channel into which money abundantly flowed; race and ethnic relations was another. But even those who remained aloof from these developments came under mounting pressure to conform to them. Today British academics, drowning in paperwork defined as accountability and transparency, are increasingly expected to be self-supporting. In some universities, heads of department set publishing targets for new faculty. In the social sciences, the small grant is no longer provided by the Economic and Social Science Research Council; its benchmark application minimum of $£ 200,000$ pushes academics towards large-scale collaboration. Knowledgetransfer, collaboration with industry and company start-ups are the rage in both the United States (especially since the Bayh-Dole Act of 1980 enabled federally funded colleges to patent their discoveries) and in Britain. A recent report from the Advanced Institute of Management Research states that of the 6000 British academics it surveyed, 38 percent of electrical and electrical engineering faculty were developing a new commercial enterprise. Exactly the same percentage hailed from the humanities, forging "predominantly consultancy-based" ventures (Salter et al. 2010: 31, 33).

If the quest for cash had simply overwhelmed the university, turning it into a commercial enterprise like any other, the LSE scandal would never have materialized. No one outside of Departments of Business or Management really expects market transactions to be governed by ethical norms; if they were, we would not buy oil from Saudi Arabia or toys from China. The market is by its very nature impersonal and, in most respects, fortunately so; the alternative would be to heavily regulate it making it less fluid, efficient and productive. Yet while the grant culture and its donation appurtenance triumphs in post-secondary education, it co-exists with a residual sense of piety-the conviction that universities exist to be special places, moral places, places where right is done. The conflation of financial exigency with lofty aspiration explains, and connects, two markedly different phenomena: why, with few qualms, the LSE could take money from a dictator's son, and why that action belatedly fuelled such indignation. The university took money from a dictator's sondependent on a dictator father - because donations are what the LSE increasingly seeks as part of its revenue stream. It took the money with a mostly good conscience because the purpose of the money appeared beneficial: global governance, deliberative democracy, cosmopolitan justice, buzz words of the enlightened mind. The LSE, more selfconsciously than any other British university, sees itself as the quintessential mover and shaper, the vanguard academic institution of social improvement. A former Director, shortly after assuming office in 1997, put it this way: "I'd like to help propel the LSE toward another golden age, and I'd like to ensure that the School has a concrete impact upon the world. The LSE has existed for more than a century and was conceived of by Sidney and Beatrice Webb as an institution which would contribute in a practical way 
to the betterment of the world" (Giddens and Pierson 1998:49).

Just over a decade later Saif al'Islam Gaddafi played to the LSE's pecuniary needs and its institutional conceit: he offered a substantial donation and he symbolized a hope of betterment. Pollution emitted by the former was salved by the purity of the latter. Conversely, from the standpoint of those outside grant-getting and donor circles, the LSE's actions look like an unscrupulous speculator gambling on democratic outcomes, its purpose as a progressive university besmirched by its desire to fund progression through a morally radioactive instrument. Yet supplicants and critics alike share one basic similarity. David Held and others sought through the offices of Saif to transmute financial taint into the gold of liberal progress; their critics damn them for betraying the progressive cause. Both parties believe that promoting progress is an inherent task of the LSE and like-minded universities.

The disorientation at the LSE and other research universities began not with dubious donors, not with financial distress, not with Scrooge-like government, but when universities lost sight of their core mission, the only thing that makes them unique and sufficiently distinctive to be worth society's support: the pursuit of knowledge and scholarship, and the practice of teaching, within a bounded intellectual community. It is the universal, salvational ambitions of the modern university, and the financial costs this agenda imposes, that made Saif al'-Islam so compelling a figure and his offer so attractive. This fact is downplayed by all those who, like Richard Sennett, view the fiasco as a result principally of stingy governments and the lack of a donor culture in British universities. This situation, he says, has made it easier for the largesse of autocrats and their progeny to be so tempting (http:/www.guardian.co.uk/commentisfree/ 2011/mar/06/universities-titian-lse-dodgy-donors.)

Sennett's regret presupposes the academic value of the centers and institutes that government penny pinching is compromising. Yet academic gargantuanism is itself also at fault. Today, thousands of centers and institutes populate Western universities. Each is self-reproducing unless an administrator winds it down. Each demands funds. Yet most could be closed with no appreciable cost in intellectual benefit. Symptomatic of this redundancy is the Centre for Global Governance's own web page that trumpets yet more studies of climate change. How much more work on this topic do we need? How much more advice can we take? How many foundations, think tanks, NGOs, politicians and others must give such advice to us? Rather than blame tightfisted government, it is sobering to ask hard questions that seem to be both implacable and irresolvable within the donation culture itself, a culture that Sennett regards as deplorably deficient in Britain
Here are some of the questions:

When critics say that the LSE was wrong to accept the donation of $£ 1.5$ million to the Centre for Global Governance from Saif al'Islam Gaddafi, what do they mean exactly? They mean that the source of the donation rather than the money itself was tarnished. Fine. But what if the source or conduit of the money-Saif-had backed the protesters in Libya, and broken with his family, during the recent turmoil? Would that have justified the LSE's accepting the donation, now being seen as proof positive of democratic intent by its main author and perhaps as embryonic influence of LSE policy on the Middle East? Or are intentions and later events irrelevant such that, as a matter of principle, one should never take money from members of despotic regimes or those connected to them? And if that is the case, is it now incumbent on all Western governments to give back all financial investments made to their universities by Saudi Arabia, China and Iran? Saudi Arabia is, by far, the biggest donor, according to Robin Simcox's report for The Centre for Social Cohesion, a British think tank. Simcox, sounding the alarm 2 years ago, notes that King Fahd gave $£ 20$ million to Oxford University's Centre for Islamic Studies; that "the University of Cambridge received $£ 8 \mathrm{~m}$ from Prince Alwaleed of Saudi Arabia, via the Kingdom Foundation, to establish the HRH Prince Alwaleed Bin Talal Centre of Islamic Studies;" that the University of Edinburgh "received $£ 8 \mathrm{~m}$ to establish the Alwaleed Bin Talal Centre of the Study of Islam in the Contemporary World. As part of the agreement, Alwaleed is allowed to pick appointees on the management committees at both Centres (for the full report see http://www.socialcohesion. co.uk/files/1238334247_1.pdf)

Here are more questions: Did the money given to the Centre for Global Governance come with strings attached or can it be used at the LSE's professional discretion? And if the latter, if it can be used to promote a more open Libya, why should the money be refused? Or can a more open Libya not be envisaged? Or, if it can be envisaged, should Westerners stay out of it? Should the donation be refused because accepting it helps burnish the credentials of a brutal regime? Or is that less important than the good it might do by exposing Libyan students, civil servants and others to different ways of conceiving of politics and society? And if lending legitimacy to dictatorships is the problem, should we then stop sending academics and jurors to China to advise on the rule of law and related issues, and discourage academics going to Iran for conferences on diversity and global justice?

The point of such questions and their corollaries is that they do not lend themselves to a moral slide rule once the donor culture is in place. It is quite possible, moreover, that Saif was sincere about Libya's reform when he was at LSE, quite possible, too, that if reform 
had proceeded more slowly he might have been one of its agents.

David Held writes that

I have known Saif al-Islam Gaddafi for several years since he did a PhD at the LSE. During this time I came to know a young man who was caught between loyalties to his family and a desire to reform his country. In many discussions and meetings I encouraged the development of his reform agenda and subsequently supported it through research on the North Africa Programme funded by the Gaddafi International Charity and Development foundation. My support fort Saif al-Islam Gaddafi was always conditional on his resolving the dilemma that he faced in a progressive and democratic direction. The speech last night makes it abundantly clear that his commitment to transforming his country has been overwhelmed by the crisis he finds himself in. $\mathrm{He}$ tragically, but fatefully, made the wrong judgment" (Personal Statement by David Held on Gaddafi's LSE Donation).

This statement is plausible. Held and others could not have known what was to transpire with Saif. Nor could Saif himself be certain. Saif's choice illuminated the conundrum of a man straddling two worlds, each with its own expectations. Crisis revealed his priorities. Tripoli outshone London. Clan loyalty bested Social Justice. Family honor eclipsed cosmopolitan virtue. Resolution born of emergency trumped the abstruse ruminations of deliberative democracy. It is basic to tribal organization that one protects those closer in kin membership in preference to those more distant, not to mention non-tribal competitors and other nations (Salzman 2009). Saif acted as most Arabs would have acted with his family background and in his position. He chose not world betterment, not Progress, but blood and regime, strangers to the academic seminar.

The LSE-Gaddafi affair may well be remembered as the moment that the research university, hitherto inured to grants and a beggar to donors, began fundamentally to reappraise its purpose. Or it might come simply to be seen as an embarrassing interregnum before business proceeds as usual. A major complication is the worsening environment of undergraduate teaching both in North America and the United Kingdom; research, funded by grants and donations, is attractive not only for the money and status it brings but also as a release from the travails of student exposure. Today many university teachers are demoralized by students who do not wish to study, who learn little (the majority), and who, flushed with a sense of entitlement, are increasingly litigious about their grades (a growing number). A recent study of the American scene reveals that "three semesters of college education ... have a barely noticeable impact [a seven percentile gain] on students' skills in critical thinking, complex reasoning and writing" (Arum and Roksa 2011: 35); nor do the subsequent five semesters have greater impact. Yet while there is much to re-think-how many universities do we need? Who should go there? Who should not?-academics in Britain and elsewhere are ill equipped to provide an alternative vision. Ideological commitments privilege solidarity over independence of mind. Specialization narrows our vision. Relativism blurs our sense of moral boundaries. Libyans in Benghazi risked all for their independence. University academics, if the recent past is any guide, are unlikely to follow their example any time soon.

\section{Further Reading}

Arum, R., \& Roksa, J. 2011. Academically adrift. Limited learning on college campuses. Chicago: University of Chicago Press.

Giddens, A., \& Pierson, C. 1998. Conversations with Anthony Giddens. Stanford: Stanford University Press.

Nisbet, R. A. 1992. Teachers and scholars. A memoir of Berkeley in depression and war. New Brunswick, N.J: Transaction Publishers.

Salter, A., Tartari, V., D'Este, P., \& Neely, A. 2010. The republic of engagement. Exploring UK Academic attitudes to collaborating with industry and entrepreneurship. London: EPSRC/ESRC.

Salzman, P. C. 2009. Tribes and terror in the Middle East. Society, 46 (5), 394-397.

Peter Baehr, International Advisory Editor of Society, is Professor of Social Theory and Academic Dean of Social Science at Lingnan University, Hong Kong. 